\title{
Stability Charts for Closely Spaced Strip Footings on Hoek-Brown Rock Mass
}

\author{
Suraparb Keawsawasvong $\cdot \operatorname{Jim}$ Shiau $(\mathbb{D} \cdot$ Khemmapa Limpanawannakul $\cdot$ Suttikarn Panomchaivath
}

Received: 28 June 2021 / Accepted: 23 January 2022 / Published online: 10 February 2022

(C) The Author(s) 2022

\begin{abstract}
Footings are constructed closely to each other in mountainous rock areas and the determination of closely spaced bearing capacity footings on rock masses has become an important topic of recent research. The primary aim of this paper is to determine an efficiency factor, just like in the design of a pile group, that can be used to evaluate the bearing capacity of closely spaced footings on Hoek-Brown mass. The advanced finite element limit analysis of upper and lower bound theorems is used to study the stability of two and multiple interfering footings using the Hoek-Brown parameters such as GSI (geological strength index) and $m_{i}$ (Hoek-Brown yield parameter). This study found that the efficiency factor is influenced by three dimensionless parameters including $G S I, m_{i}$, and $S / B$. Failure mechanisms of the problems are also investigated, and stability charts and tables produced for practical uses. Overall, these results broadly support the common understanding of the two key parameters $G S I$ and $m_{i}$ in the HB failure criterion. As a result of these investigations, suggestions were identified for future research.
\end{abstract}

Keywords Bearing capacity - Interference $\cdot$ HoekBrown yield criterion $\cdot$ Rock mass $\cdot$ Limit analysis

S. Keawsawasvong · K. Limpanawannakul ·

S. Panomchaivath

Department of Civil Engineering, Thammasat

School of Engineering, Thammasat University,

Pathumthani 12120, Thailand

J. Shiau $(\bowtie)$

School of Civil Engineering and Surveying, University

of Southern Queensland, Toowoomba, QLD 4350,

Australia

e-mail: jim.shiau@usq.edu.au

\section{Introduction}

Footings are constructed on rock masses in many hilly areas and the determination of their bearing capacity is of considerable importance in the design and construction process. This is especially so when the footings are closely spaced. The overlapping effects in rock masses induced by surrounding footings cannot be ignored. This research proposes an efficiency factor accounting for the interference effect of closely spaced strip footings on rock masses. The interference effect in this study is defined using an efficiency factor that is a ratio between the ultimate bearing capacity of a group of footings and that of a single isolated footing.

The non-linear failure criterion for intact rock or heavily jointed rock masses was first developed by Hoek and Brown (1980). Using a large number of triaxial test data of intact and jointed rocks, a curvefitting method was employed to develop the wellknown Hoek-Brown failure criterion. Hoek et al. (2002) further revised their previous work and proposed new parameters that can be used to capture the failure behaviour of highly fractured rock media. By using the latest Hoek-Brown yield criterion, many researchers have since studied the bearing capacity of a single isolated footing on rock mass (e.g., Serrano and Olalla 1994, 1998a, b; Yang and Yin 2005; Merifield et al. 2006; Saad et al. 2008; Mao et al. 2012; Kumar and Mohapatra 2017; Ukritchon and Keawsawasvong 2018; Mansouri et al. 2019; Keawsawasvong et al. 2021).

Footings are constructed closely to each other on numerous occasions, with a goal to efficiently transfer the loads to underneath rock masses. This can result 
in the interference of imposed stresses in rock masses induced by surrounding footings. The interference effect of two adjacent strip footings on soils has been studied by numerous researchers in the past (e.g., Stuart 1962; Das and Larbi-Cherif 1983; Kumar and Ghosh 2007a, b; Kumar and Kouzer 2008; Mabrouki et al. 2010; Pal et al. 2016; Lavasan et al. 2018). The early study towards understanding the interference effect of two adjacent strip footings on sandy soils was conducted by Stuart (1962), who defined an efficiency factor that is a ratio between the ultimate bearing capacity of two adjacent footings and that of a single isolated footing. The laboratory model test was later carried out by Das and Larbi-Cherif (1983) to compare results with the theoretical study by Stuart (1962). Kumar and Ghosh (2007a, b) employed the stress characteristics and upper bound methods to evaluate the ultimate bearing capacity of two adjacent strip footings on cohesionless soil by considering the full ranges of the distance between two footings and the internal friction angle of sand. The same problem was re-visited by Kumar and Kouzer (2008) using finite element lower bound analysis. Mabrouki et al. (2010) presented the efficiency factors of two footings on cohesive-frictional soils, where the impact of surcharge loading was considered. The bearing capacity of two closely spaced skirted strip foundations in sand was also investigated by Pal et al. (2016) and Lavasan et al. (2018). The efficiency factor of multiple equally spaced strip footings on cohesionless soils was also considered by Kumar and Bhattacharya (2010) and Yang et al. (2017).

The aforementioned studies were considered merely for the soil foundation. It is not uncommon to see adjacent footings be constructed in mountainous areas that requires the employment of the Hoek-Brown yield criterion for rock mass. Very recently, two closely spaced strip footings on Hoek-Brown rock masses were investigated by Shamloo and Imani (2021) using the analytical upper bound theorem, which requires an assumption of failure mechanism of two strip footings. This study therefore set out to assess the efficiency factor of two distinct interference problems, namely the two closely spaced strip footings and the multiple closely spaced strip footings on Hoek-Brown rock masses. The advanced upper bound (UB) and lower bound (LB) finite element limit analysis (FELA), which does not require a presumption, is employed to numerically study the efficiency factors. The rigorous UB and LB solutions can be used to assist in the design of a group of strip footings founded on rock mass with great confidence.

\section{Problem Statement}

\subsection{Assumptions}

In this study, the numerical technique of the finite element limit analysis (FELA) is employed to solve the bearing capacity and the efficiency factor of a group of footings on rock masses. The rock masses are modelled by volume elements and obey a rigid-perfectly plastic Hoek-Brown material under drained conditions. The footings are represented by rigid plate elements and a fully rough condition is specified for the contact interface between all footings and rocks.

The Hoek-Brown (HB) model is adopted as a failure criterion for rock masses. This failure criterion can be expressed by a power-law function in terms of the major and minor principal stresses (i.e., $\sigma_{1}$ and $\sigma_{3}$ ), where tensile normal stresses are taken as positive as shown in Eq. (1) (Hoek et al. 2002).

$\sigma_{3}=\sigma_{1}-\left(-m_{b} \sigma_{1}\left(-\sigma_{c i}\right)^{(1-a) / a}+s\left(-\sigma_{c i}\right)^{1 / a}\right)^{a}$

where $\sigma_{c i}$ is the uniaxial compressive strength of intact rock mass. The mathematic functions of the parameters $m_{b}, s$, and $a$ are expressed in the following relationship as shown in Eqs. (2) to (4).

$$
\begin{aligned}
& a=\frac{1}{2}+\frac{1}{6}\left\{\exp \left(\frac{-G S I}{15}\right)-\exp \left(\frac{-20}{3}\right)\right\} \\
& m_{b}=m_{i} \exp \left(\frac{G S I-100}{28-14 D}\right) \\
& s=\exp \left(\frac{G S I-100}{9-3 D}\right)
\end{aligned}
$$

In the above expressions, the parameter GSI (geological strength index) ranges from 10 for an extremely poor rock mass to 100 for an intact rock mass. In Hoek et al. (2002). the parameter $m_{i}$ (Hoek-Brown yield parameter) refers to the yield parameter corresponding to a frictional strength of a rock mass. The parameter $D$ (degree of disturbance) is a disturbance factor that varies from 0 (undisturbed 
in-situ rock masses) to 1 (extremely disturbing in-situ rock masses).

\subsection{Modelling}

The first problem considered here is a twin strip footing. Shown in Fig. 1a is the footing width $B$ that is subject to a limit vertical pressure of $q$, i.e. the bearing capacity of the footing. The edge-to-edge distance of the twin footings is denoted by $S$. The dashed line $\mathrm{AE}$ indicates the line of symmetry. Only half of the domain is needed, and this is shown in Fig. 1b. For the symmetrical problem, the nodes on the left-hand side boundary are prevented from moving horizontally. This boundary condition is the same for the nodes at the far side (i.e. the right-hand side boundary), which are fixed in the $\mathrm{x}$ direction. The bottom nodes are fixed in both directions whilst the top boundary is a free surface. In this problem, the sizes of the right and bottom boundaries are carefully selected to be large enough (approximately 19B and
$4 B$, respectively) so that there is no intersection of the plastic shear zone at the far side and the bottom boundaries, which can yield an error in the computed results. A typical adaptive mesh of the FELA analysis for half of the domain is shown in Fig. 1c.

The second problem belongs to a multiple interfering footing. The footing width $B$, the limit vertical pressure of $q$, and the edge-to-edge footing distance $S$ are the same as the twin strip footing. See Fig. 2a for the problem definition. Both dashed lines $\mathrm{CD}$ and $\mathrm{AE}$ are the symmetrical planes which are best explained with Fig. $2 b$ where a full domain was analysed for the three strip footings. The obtained failure mechanism has clearly shown the two symmetrical planes for the proposed problem of multiple interfering footings. With this understanding, the problem domain can be simplified to Fig. 2c. As in the twin footing problem, the symmetric boundary condition always requires a prevention of horizontal movement. All other boundary conditions are the same as in the twin footing problem. In this problem, to avoid the effect from insufficient boundaries, the size of the bottom
Fig. 1 Problem geometry of two interfering footings: a the statement; $\mathbf{b}$ model domain; c typical adaptive mesh

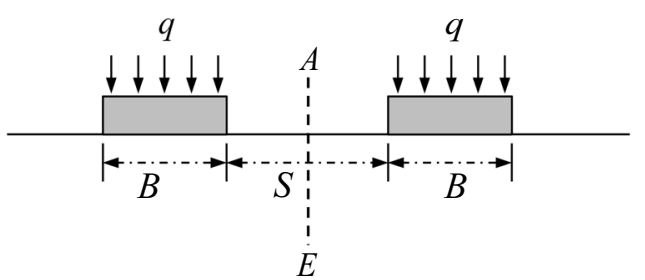

(a)

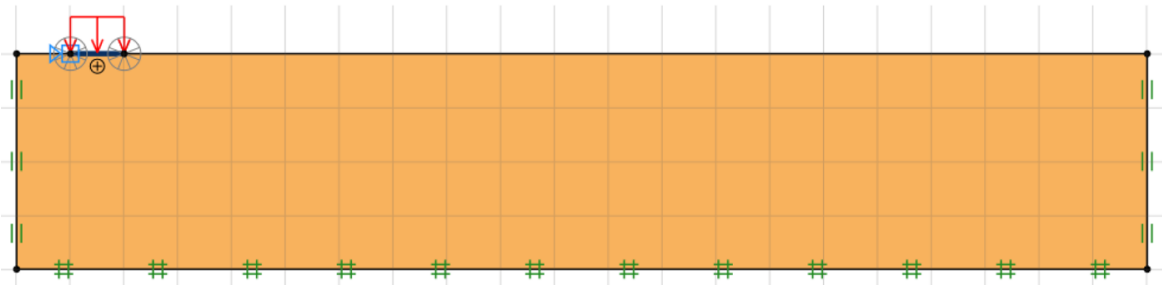

(b)

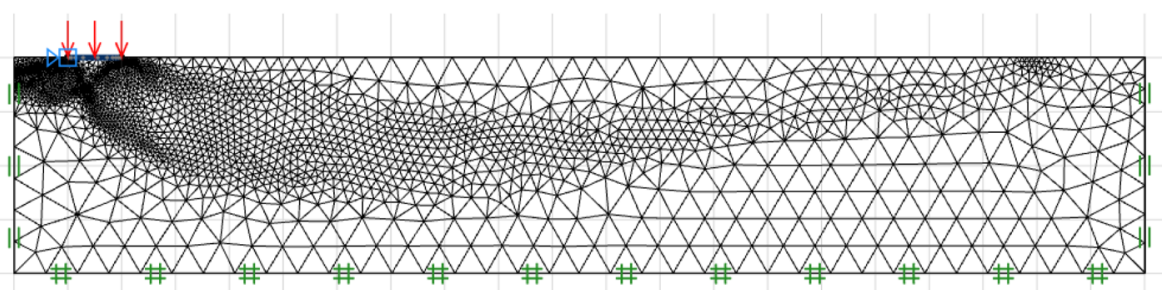

(c) 


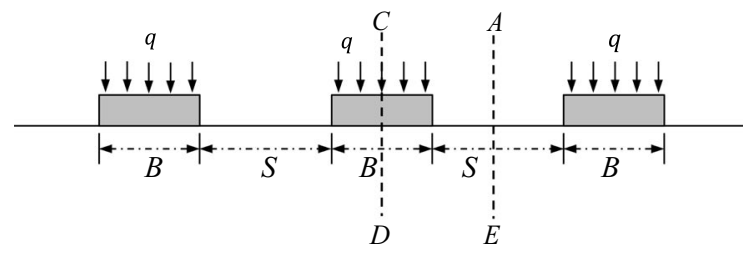

(a)

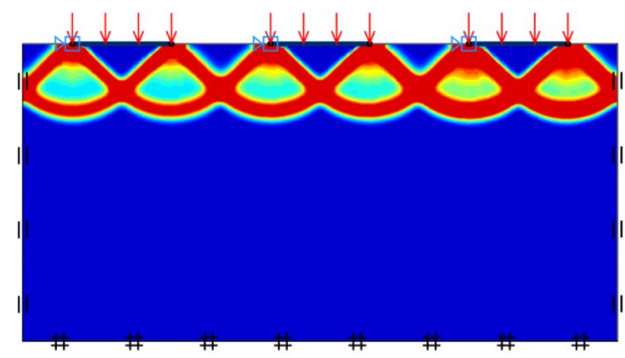

(b)

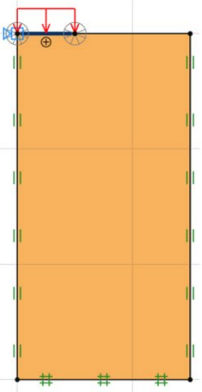

(c)

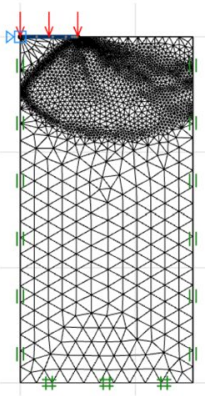

(d)
Fig. 2 Problem geometry of multiple interfering footings: a the statement; b typical failure mechanism; c model domain; d typical adaptive mesh

boundary is carefully selected to be large enough (approximately $3 B$ ). An intersection of the plastic shear zone at the bottom boundary is not allowed to take place. A typical FELA adaptive mesh for the "twin" symmetrical planes is shown in Fig. 2d. Interestingly, the adaptive mesh also shows the potential failure mechanism of the problem.

\subsection{Finite Element Limit Analysis}

The upper bound (UB) and lower bound (LB) finite element limit analysis (FELA, OptumCE 2019) has been successfully applied to several geotechnical stability problems in recent years (see e.g., Keawsawasvong and Shiau 2021a, b; Shiau et al. 2003, 2006; 2021a, b, c; Shiau and Al-Asadi 2020a, b, c, 2021a, b; Keawsawasvong et al. 2022), and it is employed to study the bearing capacity of the closely spaced footing problems using the Hoek-Brown (HB) yield criterion in this paper.

In the lower bound analysis, a linear three-node triangular element is used, where each node is associated with three unknown stresses. Each triangular element has the nodal stresses including $\sigma_{x}, \sigma_{y}$, and $\tau_{x y}$ are set to be the basic unknown variables for the plane strain problem. The statically admissible stress discontinuities are allowed for producing the continuity of normal and shear stresses along with the interfaces of all the elements. The conditions of stress equilibrium, stress boundary condition, and the Mohr-Coulomb failure criterion are all constraints in a typical LB analysis, in which the objective function is to maximize the limit vertical pressure of two interfering footings or multiple interfering footings by using equilibrium equations, where stress boundary conditions and the yield criterion are satisfied. The expression of Mohr-Coulomb failure criterion in conjunction with tensile normal stresses taken as positive at a point can be represented by Eq. (5).

$\sqrt{\left(\sigma_{x}-\sigma_{y}\right)^{2}+\left(\sigma_{x}-\tau_{x y}\right)^{2}}-2 c \cot \phi-\left(\sigma_{x}-\sigma_{y}\right) \sin \phi \leq 0$

In the upper bound theorem, a six-node triangular element is adopted for the upper bound analysis, where each node contains two unknown velocities that vary quadratically within the triangular element. At each node of the element, there are the horizontal $(u)$ and vertical velocities (v) defined as the basic unknown variables. The setting of kinematically admissible velocity discontinuities is applied at the interfaces of all the elements. The material is set to obey the associated flow rule so that Eq. (6) is satisfied along any velocity discontinuity.

$\Delta v-|\Delta u| \tan \phi=0$

where $\Delta u$ and $\Delta v$ are the tangential and the normal velocity jumps along the discontinuity. The formulated objective function is to minimise the limit vertical pressure of either two interfering footings or multiple interfering footings. More details on the LB and UB FELA can be found in Sloan (2013).

The automatic mesh adaptivity function is used in all analyses. The scheme of this adaptive mesh refinement is based on the work of Ciria et al. (2008). In 
this procedure, several elements increase in certain sensitive regions of simulation during the time of calculation (Keawsawasvong and Ukritchon 2017; Ukritchon and Keawsawasvong 2017). For numerical simulations in this study, three adaptive refinement steps are selected by increasing the number of elements from 5000 elements at the first step to approximately 10,000 elements at the final step. Note that the first, second, and third steps correspond to the differences between the UB and LB solutions approximately about 10,8 , and $5 \%$, respectively. As a result, this study employs the setting of three adaptive refinement steps since the 5\% difference is acceptable for FELA results with $\mathrm{HB}$ failure criterion (Keawsawasvong 2021; Keawsawasvong et al., 2021, 2022; Yodsomjai et al. 2021a; 2021b; Keawsawasvong and Ukritchon 2020). The examples of final adaptive meshes after three adaptive refinement steps are shown in Figs. 1c and $2 \mathrm{~d}$ for two interfering footings and multiple interfering footings, respectively.

\subsection{Limitations}

The main Hoek-Brown parameters for rock masses considered in this paper are the parameter GSI (geological strength index) and the parameter $m_{i}$ (Hoek-Brown yield parameter). Table 1 shows the details of parametric values considered. It should be noted that this study is concerned with the rock masses under undisturbed in-situ conditions and the disturbance factor $D$ is assumed to be zero. Also note that the effects of rock unit weight $(\gamma)$ and surcharge $(q)$ are not considered in the study due to their negligible effect. In addition, the foundation roughness of all strip footings is assumed to be rough in all numerical simulations. This is similar to several previous studies of a single footing on HB rock mass by Yang and Yin (2005), Keawsawasvong (2021), Keawsawasvong et al. (2021), and Yodsomjai et al. (2021a). More information regarding the effects of rock unit weight $(\gamma)$ and surcharge $(q)$ on the bearing capacity of a single footing can be found in Merifield et al. (2006).

\section{The Efficiency Factor and Hoek-Brown Failure Criterion}

In this study, the efficiency factor of two interfering footings and multiple interfering footings is denoted
Table 1 List of parametric values used for modelling the footing and Hoek-Brown material

\begin{tabular}{ll}
\hline Parameters & Selected values \\
\hline$S / B$ & $1-30$ \\
$m_{i}$ & $5-35$ \\
$G S I$ & $30-100$ \\
$D$ & 0 \\
$\Gamma$ & 0 \\
\hline
\end{tabular}

by $\xi$, which is the ratio of the ultimate bearing capacity of two interfering footings $\left(q_{t w o}\right)$ to the ultimate bearing capacity of a single isolated footing $\left(q_{\text {single }}\right)$. For multiple interfering footings, the $\xi$ ratio is defined as $\left(q_{\text {multiple }}\right) /\left(q_{\text {single }}\right)$. On the other note, the efficiency factor $\xi$ is the ratio between the ultimate bearing capacity solutions between a group of footings and a single isolated footing, as shown in Eqs. (7) and (8).

$x=\left(q_{\mathrm{two}} / q_{\text {single }}\right) \quad$ for two interfering footings

$x=\left(q_{\text {multiple }}\right) /\left(q_{\text {single }}\right)$ for multiple interfering footings

The efficiency factor is a function of three dimensionless parameters including the geological strength index $G S I$, the HB yield parameter $m_{i}$, and the spacing ratio $S / B$ as shown in Eq. (9).

$\xi \propto f\left(G S I, m_{i}, \frac{S}{B}\right)$

Note that GSI and $m_{i}$ are literally a dimensionless coefficient, which does not require to be normalised (Merifield et al. 2006; Keawsawasvong et al. 2021; Keawsawasvong 2021; Yodsomjai et al. 2021a).

Throughout the present study, the effects of the spacing ratio $(S / B)$ and the $\mathrm{HB}$ strength parameters on the efficiency factor of interfering strip footings on HB rock masses are investigated and presented in the form of design charts. The proposed efficiency factor can be conveniently used to determine the bearing capacity of a group of strip footings on rock mass. 


\section{Model Validation}

Before any parametric analyses, it is of vital importance to validate the developed numerical model. In this section, the bearing capacity factors $q / \sigma_{c i}$ of a single isolated strip footing are compared with previously published results. Both our upper bound (UB) and lower bound (LB) results are averaged $(\mathrm{AVG}=(\mathrm{UB}+\mathrm{LB}) / 2)$ and used to compare with those reported by Merifield et al. (2006) and Serrano et al. (2000). Note the solutions from Merifield et al. (2006) were the AVG solutions obtained from their UB and LB FELA analyses while the solutions from Serrano et al. (2000) were computed by using the elasto-plastic displacement-based finite element method. Table 2 summaries the percentage errors of the bearing capacity factor $q / \sigma_{c i}$. Excellent agreement is found between the present study and the previously published solutions. In general, the percentage errors are within 5\%, giving great confidence with the produced results in the paper.

\section{Two Interfering Footings}

The relationship between the efficiency factor $\xi$ and the distance ratio $S / B$ are presented in Fig. 3a-e for the different values of $m_{i}=5-35$ and $G S I=30-100$. Taking Fig. 3a for example, the efficiency factor increases dramatically as the distance ratio $S / B$ between two footings increases. At some points after reaching the peak, the efficiency factor decreases sharply as the distance ratio $S / B$ further increases and returns to unity (i.e. the problem of a single footing). This finding is similar to the previous studies of two footings on soils (e.g., Kumar and Ghosh, 2007a; 2007b; Mabrouki et al., 2010). The smaller the GSI, the larger the the efficiency factor $\xi$.
Table 2 Bearing capacity comparison $\left(q_{\text {single }} / \sigma_{c i}\right)$ of a single strip footing on rock mass

\begin{tabular}{|c|c|c|c|c|c|c|}
\hline$G S I$ & $m_{i}$ & Present Study & $\begin{array}{l}\text { Merifield et al. } \\
\text { (2006) }\end{array}$ & $\%$ Error & $\begin{array}{l}\text { Serrano et al. } \\
(2000)\end{array}$ & $\%$ Error \\
\hline 30 & 5 & 0.235 & 0.235 & 0.00 & 0.227 & 3.524 \\
\hline 30 & 10 & 0.394 & 0.397 & -0.756 & 0.393 & 0.254 \\
\hline 30 & 20 & 0.695 & 0.713 & -2.525 & 0.716 & -2.933 \\
\hline 30 & 30 & 0.990 & 1.022 & -3.131 & 1.038 & -4.624 \\
\hline 30 & 35 & 1.142 & 1.193 & -4.275 & 1.200 & -4.833 \\
\hline 50 & 5 & 0.646 & 0.644 & 0.311 & 0.638 & 1.254 \\
\hline 50 & 10 & 1.036 & 1.037 & -0.096 & 1.031 & 0.485 \\
\hline 50 & 20 & 1.747 & 1.765 & -1.020 & 1.760 & -0.739 \\
\hline 50 & 30 & 2.397 & 2.467 & -2.837 & 2.458 & -2.482 \\
\hline 50 & 35 & 2.723 & 2.817 & -3.337 & 2.801 & -2.785 \\
\hline 70 & 5 & 1.587 & 1.582 & 0.316 & 1.574 & 0.826 \\
\hline 70 & 10 & 2.450 & 2.444 & 0.245 & 2.434 & 0.657 \\
\hline 70 & 20 & 3.985 & 4.012 & -0.673 & 3.998 & 0.325 \\
\hline 70 & 30 & 5.436 & 5.491 & -1.002 & 5.470 & -0.622 \\
\hline 70 & 35 & 6.124 & 6.068 & 0.923 & 6.187 & -1.018 \\
\hline 90 & 5 & 3.888 & 3.881 & 0.180 & 3.869 & 0.491 \\
\hline 90 & 10 & 5.763 & 5.758 & 0.087 & 5.741 & 0.383 \\
\hline 90 & 20 & 9.120 & 9.125 & -0.055 & 9.100 & 0.220 \\
\hline 90 & 30 & 12.213 & 12.270 & -0.465 & 12.237 & -0.196 \\
\hline 90 & 35 & 13.648 & 13.794 & -1.058 & 13.738 & -0.655 \\
\hline 100 & 5 & 6.126 & 6.124 & 0.033 & 6.114 & 0.196 \\
\hline 100 & 10 & 8.904 & 8.896 & 0.090 & 8.875 & 0.327 \\
\hline 100 & 20 & 13.853 & 13.847 & 0.043 & 13.809 & 0.319 \\
\hline 100 & 30 & 18.400 & 18.444 & -0.239 & 18.390 & 0.054 \\
\hline 100 & 35 & 20.612 & 20.668 & -0.271 & 20.628 & -0.078 \\
\hline
\end{tabular}


Fig. 3 The variation of efficiency factor $\xi$ with $S / B$ for two interfering footings $\left(m_{i}=5-35\right.$ and $\left.G S I=30-100\right)$

The results in Fig. 3a-e also indicate that the larger the $m_{i}$ value, the larger the efficiency factor $\xi$. One interesting observation is for the distance ratio $S / B$ when the efficiency factor $\xi=1$. Taking $\left(m_{i}=5\right.$ and $G S I=30$ ) as an example (see Fig. $3 a$ ), $S / B$ is about 5 when $\xi$ returns to unity. As $m_{i}$ increases (see Fig. $3 \mathrm{e}$ for $m_{i}=35$ ), a much larger distance ratio $S / B=20$ is required for the efficiency factor $\xi$ to return to unity. This result may be explained by the fact that the parameter $m_{i}$ represents the frictional strength of a rock mass. The larger the $m_{i}$ value, the larger the distance ratio $S / B$ required for the efficiency factor $\xi$ to return to unity.

Figures $4 \mathrm{a}-\mathrm{e}$ show the efficiency factors of two interfering strip footings for the different values of $G S I=30,50,70,90$, and 100 , respectively. The results indicate that the smaller the value of GSI, the greater the efficiency factor $\xi$. Table 3 presents the results of the peak efficiency factor $\xi_{p}$ and the corresponding "peak" distance ratio $S_{p} / B$ for different values of $m_{i}$ and GSI. These "peak" values are useful in design practice as the optimum value of the interfering bearing capacity can be efficiently determined.

The failure mechanisms of two interfering strip footings on Hoek-Brown rock masses are presented in Fig. 5a and b for $m_{i}=5$ and $m_{i}=35$, respectively. For brevity, only the plots of incremental shear strain contours $\left(\varepsilon_{s}\right)$ are used to portray the effects of HB parameters and the distance ratio $S / B$. With the symmetrical domain, the overlapping effects are mostly seen in small values of $S / B$. This overlapping effect can increase the footing capacity when the value of $S / B$ is small. However, when the ratio $S / B$ becomes very large, the failure patterns become the Prandtl types of failures. For the small value of $m_{i}=5$ (see Fig. 5a), no significant differences in failure mechanism were found amongst the various distance ratios $S / B$. A possible explanation for this might be due to the low frictional strength of the rock mass when $m_{i}$ is small. Further to this, it was found that a larger value of $m_{i}$ results in a larger size of failure mechanism in the horizontal direction (see both Fig. 5a and b).

The effect of GSI on the failure mechanisms of two interfering strip footings on rock masses is presented in Fig. 6a and b for $G S I=30$ and $G S I=100$, respectively. The $m_{i}$ value is chosen as 20 for this

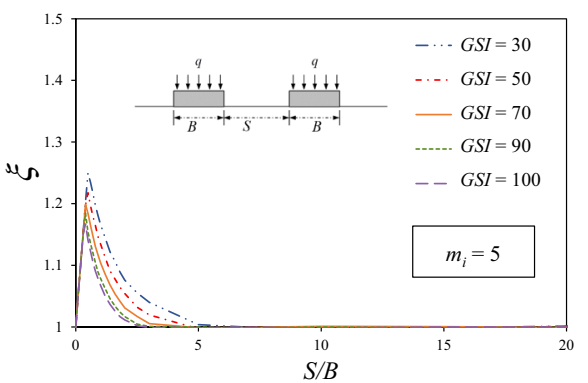

(a) $m_{i}=5$

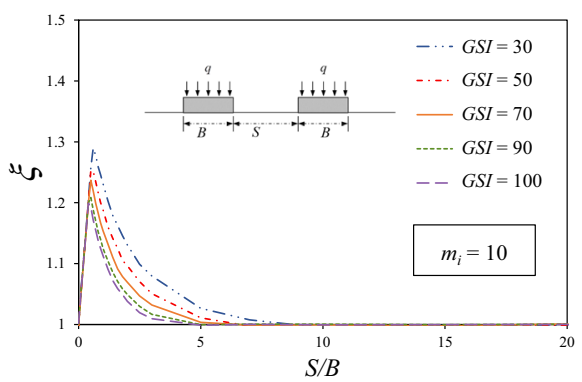

(b) $m_{i}=10$

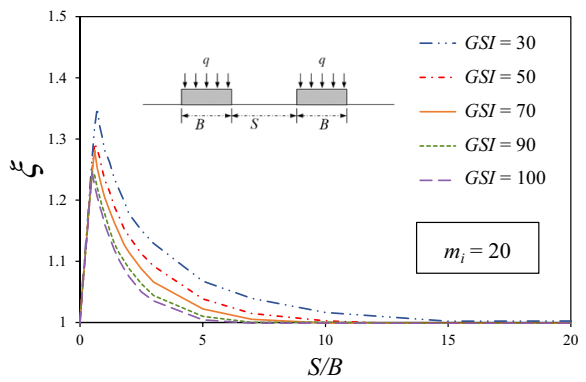

(c) $m_{i}=20$

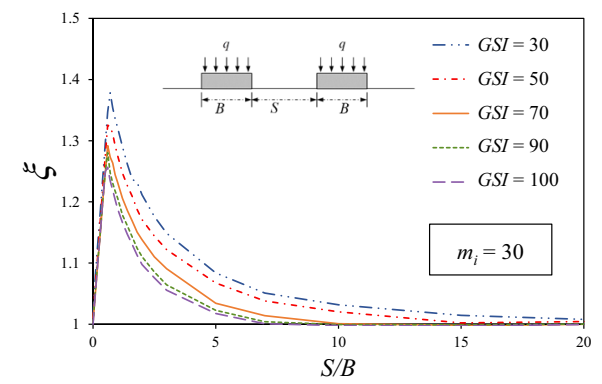

(d) $m_{i}=30$

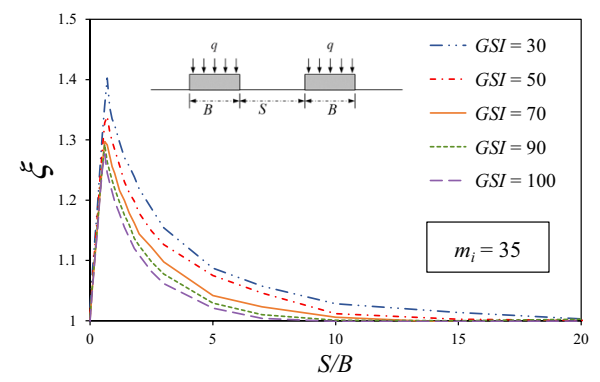

(e) $m_{i}=35$ 
Fig. 4 The variation of efficiency factor $\xi$ with $S / B$ for two interfering footings $\left(m_{i}=5-35\right.$ and $\left.G S I=30-100\right)$

comparison. This study confirms that the size of failure mechanism decreases as the GSI value increases, which is similar to the findings by Keawsawasvong et al. (2021), Keawsawasvong (2021), and Yodsomjai et al. (2021a, b). Overall, these results broadly support the common understanding of the two key parameters $G S I$ and $m_{i}$ in the HB failure criterion.

\section{Multiple Interfering Footings}

The efficiency factor $\xi$ of multiple interfering strip footings are shown in Figs. 7(a-e) for various values of $S / B, m_{i}$ and $G S I$. One interesting finding that is significantly different from the previous two interfering strip footings is the starting value of the spacing ratio $S / B$. The efficiency factor $\xi$ increases immediately to a peak value as soon as $S / B$ becomes non-zero. This finding is the same as the previous studies of multiple footings on soils (e.g., Kumar and Bhattacharya 2010; Yang et al. 2017). In Fig. 7a, $m_{i}=5$ and $G S I=30$, the peak efficiency factor $\xi=5.41$ at a minimum value of $S / B=0.1$. After reaching the peak value, an increase of $S / B$ results in a decrease of $\xi$. Besides, the larger the $m_{i}$ value, the larger the efficiency factor $\xi$. It was also found in Fig. 8a-e that the larger the GSI, the smaller the the efficiency factor $\xi$. Table 4 shows the results of the peak efficiency factor $\xi_{p}$ and the corresponding "peak" distance ratio $S_{p} / B(=0.1)$ for different values of $m_{i}$ and GSI.

Depending on the values of GSI and $m_{i}$, the efficiency factor $\xi$ drops to unity at different $S / B$ values. This is best demonstrated using the failure mechanisms of multiple interfering strip footings, shown in Figs. 9 and 10. For the small value of $m_{i}=5$ (see Fig. 9a), the footing interference become insignificant at $S / B=10$. On the other hand, for the large value of $m_{i}=35$ in Fig. 9 b, a value of $S / B=30$ is required to avoid the interference effect. The effect of GSI on the failure mechanisms of multiple interfering strip footings is presented in Fig. 10a and b for $G S I=30$ and $G S I=100$, respectively. The domains of the multiple footings have symmetrical planes on both left-handed and right-handed sides. Again, the $m_{i}$ value is chosen as 20 for this comparison. The most obvious finding to emerge from the plots is that the smaller the GSI

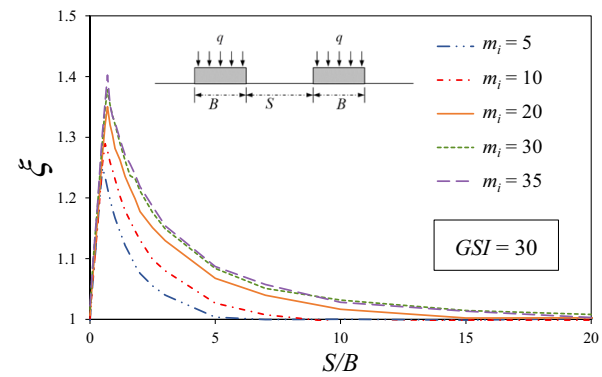

(a) $G S I=30$

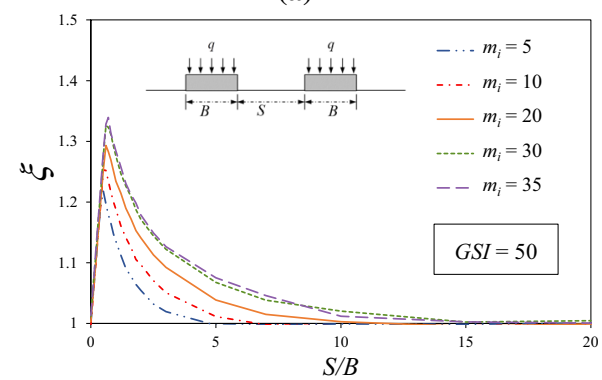

(b) $G S I=50$

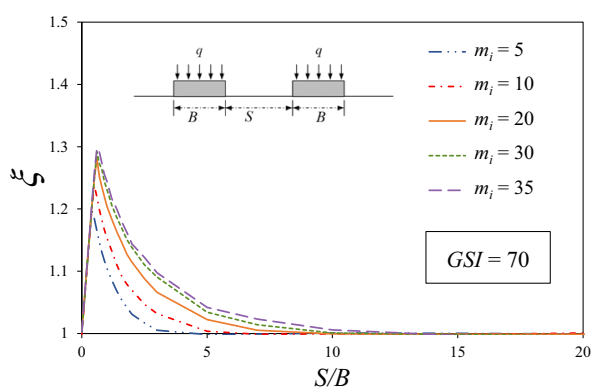

(c) $G S I=70$

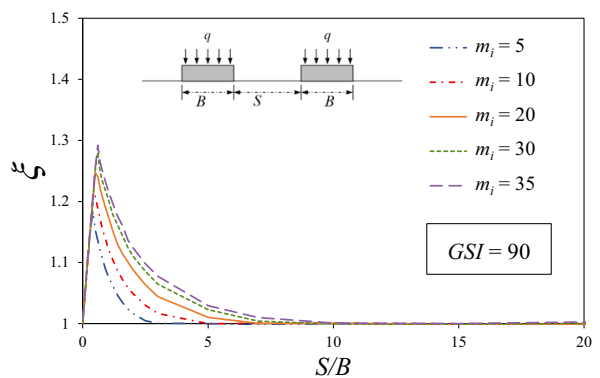

(d) $G S I=90$

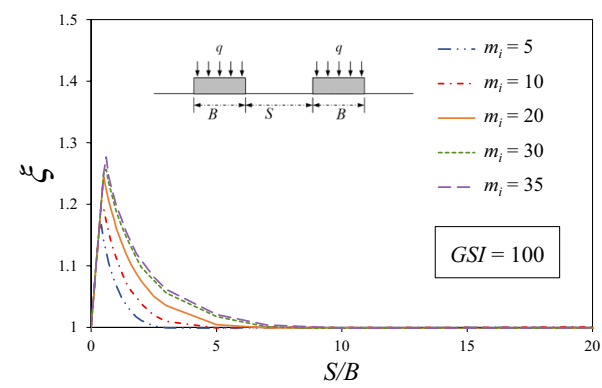

(e) $G S I=100$ 
Table $3 S_{p} / B$ versus $\xi_{p}$ of two interfering footings on rock masses

\begin{tabular}{|c|c|c|c|}
\hline$G S I$ & $m_{i}$ & $S_{p} / B$ & $\xi_{p}$ \\
\hline 30 & 5 & 0.5 & 1.25 \\
\hline 30 & 10 & 0.6 & 1.29 \\
\hline 30 & 20 & 0.7 & 1.35 \\
\hline 30 & 30 & 0.7 & 1.38 \\
\hline 30 & 35 & 0.7 & 1.40 \\
\hline 50 & 5 & 0.5 & 1.22 \\
\hline 50 & 10 & 0.5 & 1.25 \\
\hline 50 & 20 & 0.6 & 1.29 \\
\hline 50 & 30 & 0.6 & 1.33 \\
\hline 50 & 35 & 0.7 & 1.34 \\
\hline 70 & 5 & 0.4 & 1.20 \\
\hline 70 & 10 & 0.5 & 1.24 \\
\hline 70 & 20 & 0.6 & 1.28 \\
\hline 70 & 30 & 0.6 & 1.29 \\
\hline 70 & 35 & 0.6 & 1.30 \\
\hline 90 & 5 & 0.4 & 1.19 \\
\hline 90 & 10 & 0.5 & 1.21 \\
\hline 90 & 20 & 0.5 & 1.25 \\
\hline 90 & 30 & 0.6 & 1.28 \\
\hline 90 & 35 & 0.6 & 1.29 \\
\hline 100 & 5 & 0.4 & 1.17 \\
\hline 100 & 10 & 0.4 & 1.20 \\
\hline 100 & 20 & 0.5 & 1.24 \\
\hline 100 & 30 & 0.6 & 1.26 \\
\hline 100 & 35 & 0.6 & 1.28 \\
\hline
\end{tabular}

value, the larger the distance ratio $S / B$ is required to eliminate the interference effect of multiple strip footings. The impacts of $m_{i}$ and GSI on the size of the failure mechanisms are found to be the same as those previous studies in Keawsawasvong et al. (2021), Keawsawasvong (2021), and Yodsomjai et al. (2021a, b).

In general, the overlapping has a positive effect on the overall bearing capacity of multiple footings owning to the lateral resistance provided by the nearby footings. This study confirms broadly the understanding of the effects of the two key parameters GSI and $m_{i}$ in the HB rock mass.
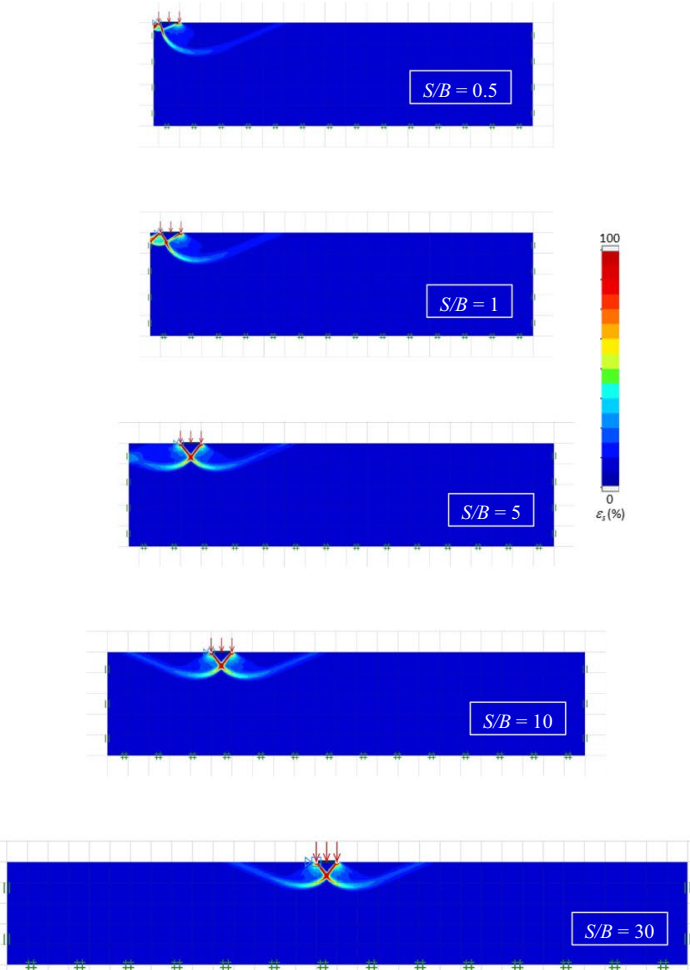

(a) $m_{i}=5$
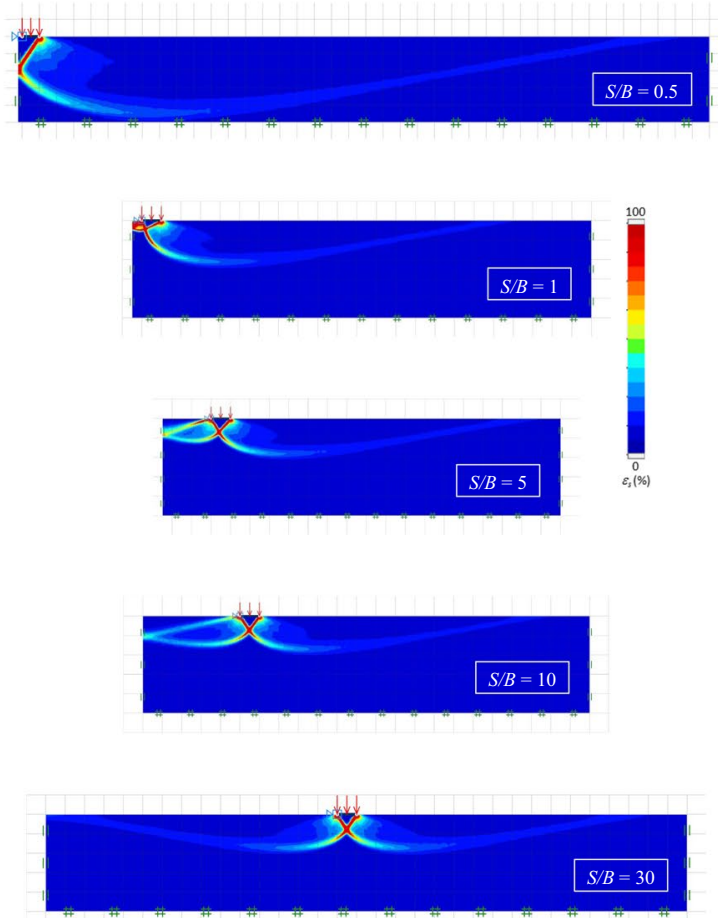

(b) $m_{i}=35$

Fig. 5 Incremental shear strain contours of two interfering footings on rock masses $(G S I=70)$ 

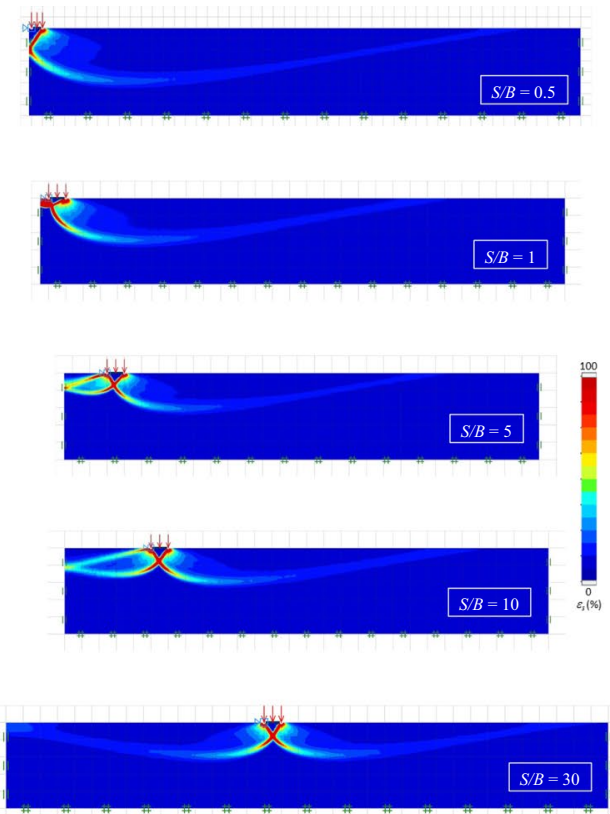

(a) $G S I=30$
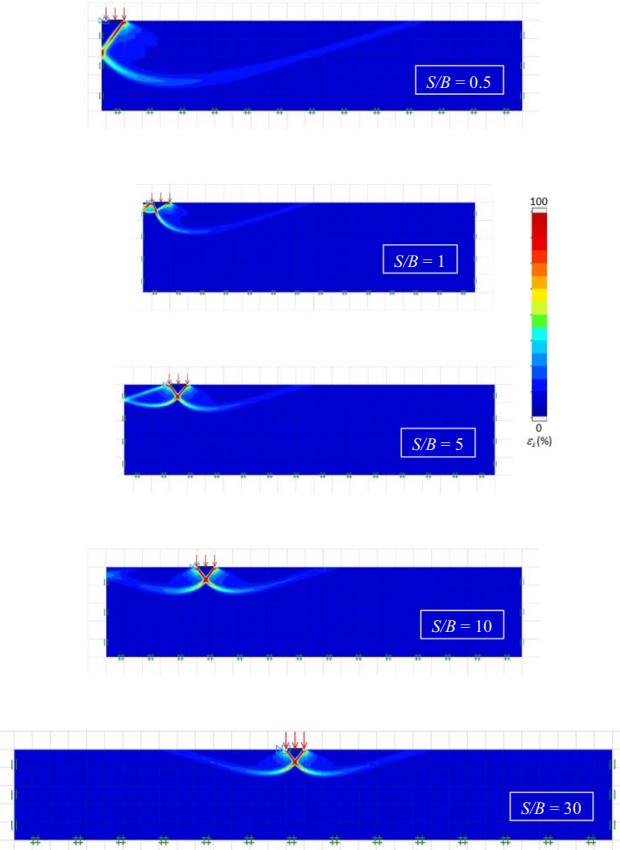

(b) $G S I=100$

Fig. 6 Incremental shear strain contours of multiple interfering footings on rock masses $\left(m_{i}=20\right)$

\section{Conclusions}

This project was undertaken to study the interference effects of closely spaced footings on Hoek-Brown rock mass. The study set out to estimate the efficiency factor $\xi$, just like in the determination of pile group efficiency, that can be used to evaluate the bearing capacity of closely spaced footings. The advanced finite element limit analysis has been proven to be both effective and efficient in producing parametric results of complex problems involving the interfering effects on rock mass. The following conclusions are drawn based on the present study.

1. This study has confirmed that the efficiency factor $\xi$ is a function of three dimensionless parameters, namely the geological strength index GSI, the HB yield parameter $m_{i}$, and the spacing ratio $S / B$. An increase in $m_{i}$ results in an increase in $\xi$ whereas an increase in GSI yields a decrease in $\xi$. The relationships between the efficiency factor $\xi$ and the spacing ratio $S / B$ for the cases of two footings and multiple footings on rock masses are in the same tendencies as the previous studies for those footings on soils.

2. Complete design charts covering a wide range of the three parameters were produced for practical uses. To use these proposed charts, the value of the bearing capacity $\left(q_{\text {single }} / \sigma_{c i}\right)$ of a single footing is firstly taken from Table 2 . Then, the bearing capacity of two interfering footings $\left(q_{t w o}\right)$ and multiple interfering footings $\left(q_{\text {multiple }}\right)$ can be obtained from $q_{\text {two }}$ and $q_{\text {multiple }}=q_{\text {single }} \times \xi$, where the efficiency factor $\xi$ can be obtained from Figs. 3 and 4 and Figs. 7 and 8 for two interfering footings and multiple interfering footings, respectively.

3. The results of the peak efficiency factor $\xi_{p}$ and the peak distance ratio $S_{p} / B$ for different values of $m_{i}$ and GSI are reported in the paper. These optimum values can be used in the design practice for predicting the peak distance ratio of closely spaced footings on rock masses.

4. This study has also shown that the size of failure mechanism decreases as the GSI value increases. Owing to the low frictional strength of the rock mass, very little changes in the size of failure mechanism was observed when $m_{i}$ is small. Overall, these results broadly support the common 


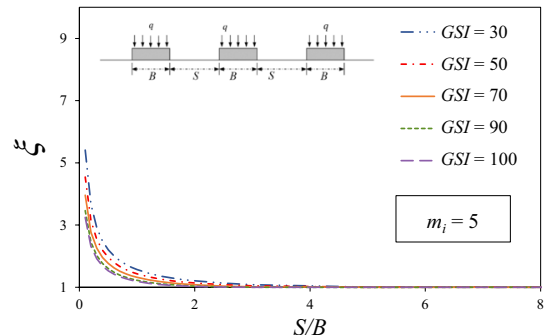

(a) $m_{i}=5$

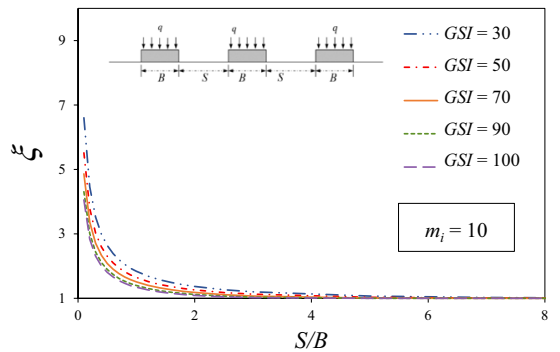

(b) $m_{i}=10$

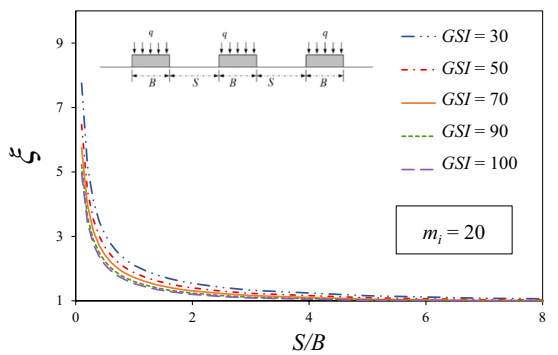

(C) $m_{i}=20$

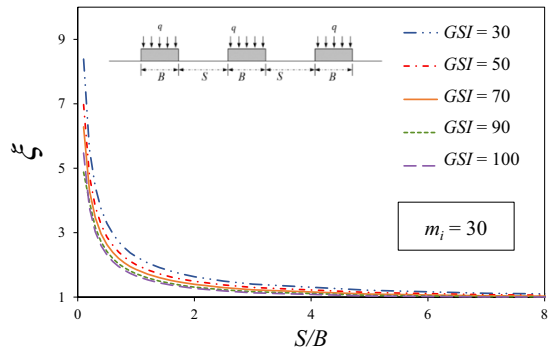

(d) $m_{i}=30$

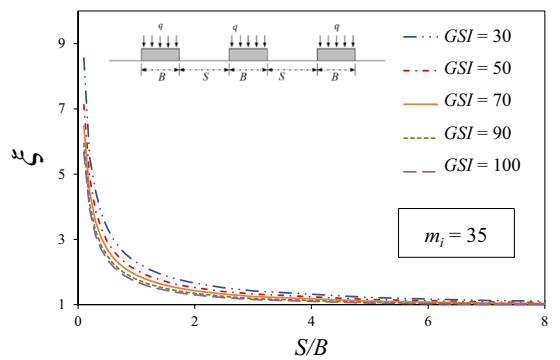

(e) $m_{i}=35$
Table $4 S_{p} / B$ versus $\xi_{p}$ of multiple interfering footings on rock masses

\begin{tabular}{|c|c|c|c|}
\hline$G S I$ & $m_{i}$ & $S_{p} / B$ & $\xi_{p}$ \\
\hline 30 & 5 & 0.1 & 5.41 \\
\hline 30 & 10 & 0.1 & 6.60 \\
\hline 30 & 20 & 0.1 & 7.75 \\
\hline 30 & 30 & 0.1 & 8.39 \\
\hline 30 & 35 & 0.1 & 8.56 \\
\hline 50 & 5 & 0.1 & 4.54 \\
\hline 50 & 10 & 0.1 & 5.51 \\
\hline 50 & 20 & 0.1 & 6.47 \\
\hline 50 & 30 & 0.1 & 6.98 \\
\hline 50 & 35 & 0.1 & 7.13 \\
\hline 70 & 5 & 0.1 & 3.96 \\
\hline 70 & 10 & 0.1 & 4.86 \\
\hline 70 & 20 & 0.1 & 5.76 \\
\hline 70 & 30 & 0.1 & 6.28 \\
\hline 70 & 35 & 0.1 & 6.48 \\
\hline 90 & 5 & 0.1 & 3.46 \\
\hline 90 & 10 & 0.1 & 4.31 \\
\hline 90 & 20 & 0.1 & 5.22 \\
\hline 90 & 30 & 0.1 & 4.88 \\
\hline 90 & 35 & 0.1 & 5.95 \\
\hline 100 & 5 & 0.1 & 3.25 \\
\hline 100 & 10 & 0.1 & 4.05 \\
\hline 100 & 20 & 0.1 & 4.96 \\
\hline 100 & 30 & 0.1 & 5.47 \\
\hline 100 & 35 & 0.1 & 5.67 \\
\hline
\end{tabular}

Fig. 7 The variation of efficiency factor $\xi$ with $S / B$ for multiple interfering footings $\left(m_{i}=5-35\right.$ and $\left.G S I=30-100\right)$ 


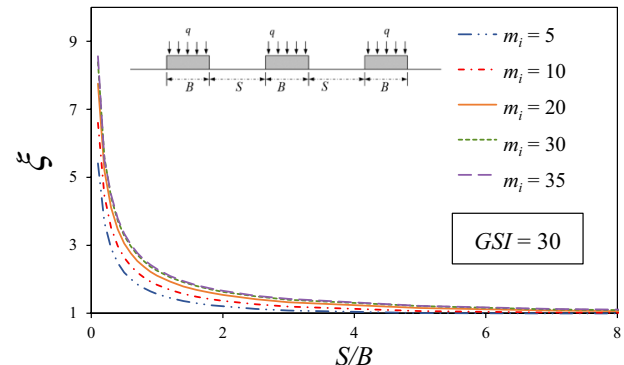

(a) $G S I=30$

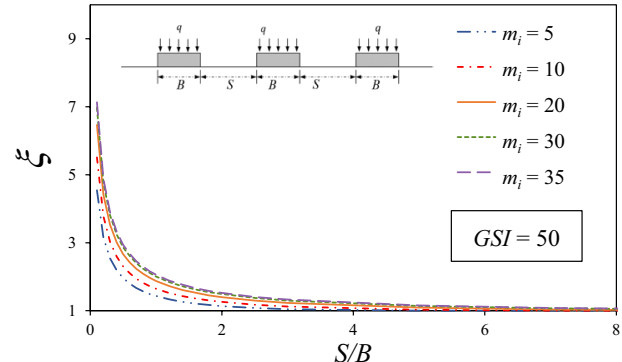

(b) $G S I=50$

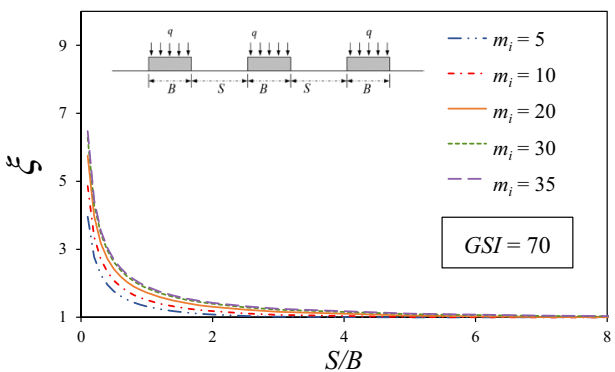

(c) $G S I=70$

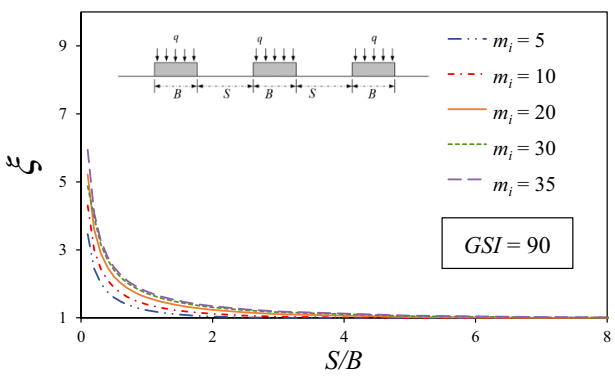

(d) $G S I=90$

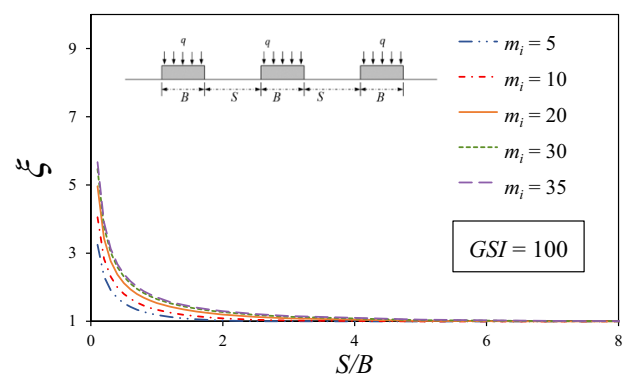

(e) $G S I=100$
4 Fig. 8 The variation of efficiency factor $\xi$ with $S / B$ for multiple interfering footings $\left(m_{i}=5-35\right.$ and $\left.G S I=30-100\right)$ 
Fig. 9 Incremental shear strain contours of multiple interfering footings on rock masses $(G S I=70)$
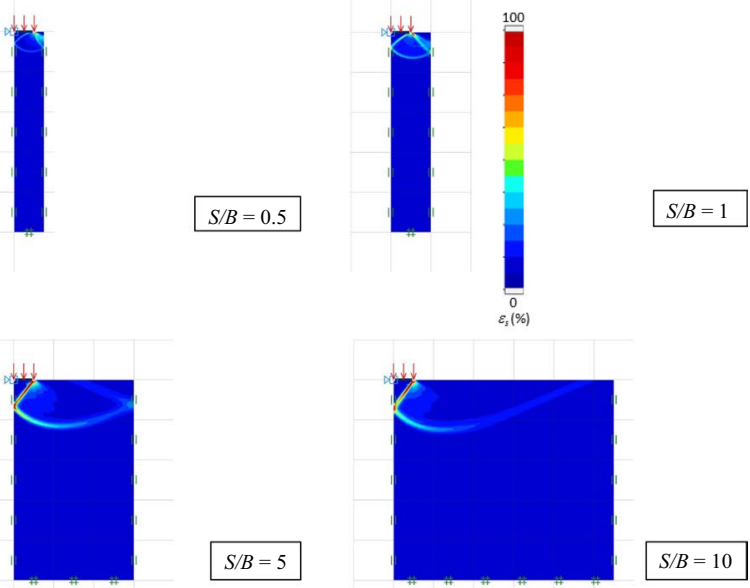

$S / B=5$

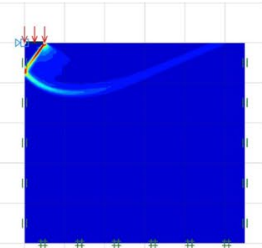

(a) $m_{i}=5$
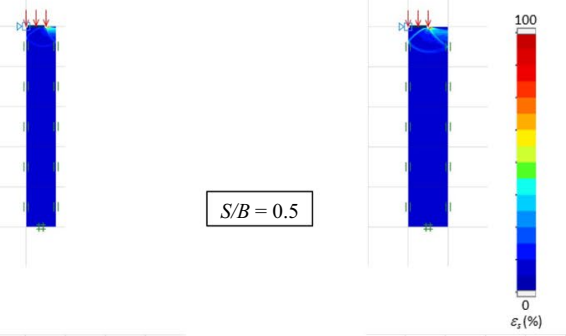

$S / B=1$

$S / B=0.5$

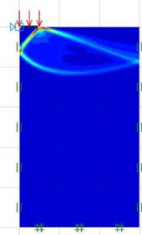

$S / B=5$

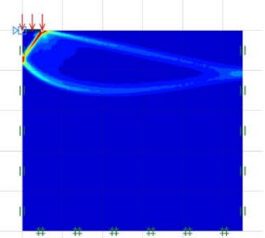

$S / B=10$

(b) $m_{i}=35$ 
Fig. 10 Incremental shear strain contours of multiple interfering footings on rock masses $\left(m_{i}=20\right)$
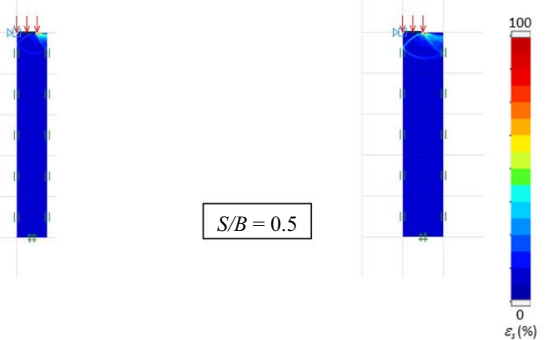

$S / B=1$

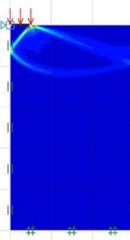

$$
S / B=5
$$

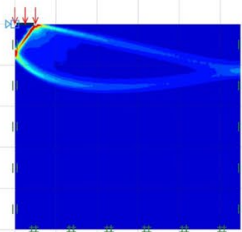

$S / B=10$

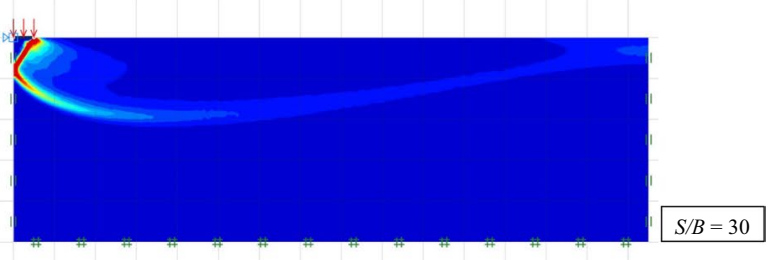

(a) $G S I=30$
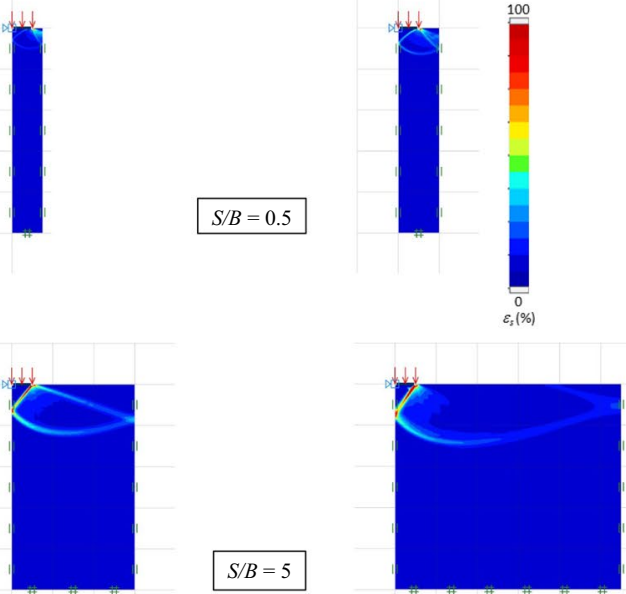

$S / B=10$

$$
S / B=5
$$

(b) $G S I=100$ 
understanding of the two key parameters GSI and $m_{i}$ in the HB failure criterion.

\begin{abstract}
Authors' Contributions Suraparb Keawsawasvongacquired methodology, software, conceptualization and provided resources, writing - original draft. Jim Shiau - acquired methodology, supervision and contributed to conceptualization, writing - original draft, review, and editing. Khemmapa Limpanawannakul-acquired software and contributed to investigation and data curation. Suttikarn Panomchaivathacquired software and contributed to investigation and data curation.
\end{abstract}

Funding Open Access funding enabled and organized by CAUL and its Member Institutions. The authors have not disclosed any funding.

Data Availability The data and materials in this paper are available.

\section{Declarations}

Conflict of interest The authors declare that they have no conflicts of interest to this work.

Open Access This article is licensed under a Creative Commons Attribution 4.0 International License, which permits use, sharing, adaptation, distribution and reproduction in any medium or format, as long as you give appropriate credit to the original author(s) and the source, provide a link to the Creative Commons licence, and indicate if changes were made. The images or other third party material in this article are included in the article's Creative Commons licence, unless indicated otherwise in a credit line to the material. If material is not included in the article's Creative Commons licence and your intended use is not permitted by statutory regulation or exceeds the permitted use, you will need to obtain permission directly from the copyright holder. To view a copy of this licence, visit http://creativecommons.org/licenses/by/4.0/.

\section{References}

Ciria H, Peraire J, Bonet J (2008) Mesh adaptive computation of upper and lower bounds in limit analysis. Int $\mathbf{J}$ Numer Meth Eng 75:899-944

Das BM, Larbi-Cherif S (1983) Bearing capacity of two closely spaced shallow foundations on sand. Soils Found 23(1):1-7

Hoek E, Brown ET (1980) Empirical strength criterion for rock masses. J Geotech Eng Div 106(9):1013-1035

Hoek E, Carranza-Torres C, Corkum B (2002) Hoek-Brown failure criterion-2002 edition. In: Proceedings of the North American rock mechanics society meeting in Toronto, Canada.
Keawsawasvong S (2021) Bearing capacity of conical footings on Hoek-Brown rock masses using finite element limit analysis. Int J Comput Mater Sci Eng 10(3):2150015

Keawsawasvong S, Shiau J (2021a) Instability of boreholes with slurry. Int J Geosynth Ground Eng 7(4):1-11

Keawsawasvong S, Shiau J (2021b) Stability of active trapdoors in axisymmetry. Underground Space. https://doi. org/10.1016/j.undsp.2021.05.001

Keawsawasvong S, Shiau J, Ngamkhanong C, Lai VQ, Thongchom C (2022) Undrained stability of ring foundations: axisymmetry, anisotropy, and nonhomogeneity. Int J Geomech 22(1):04021253. https://doi.org/10.1061/ (ASCE)GM.1943-5622.0002229

Keawsawasvong S, Thongchom C, Likitlersuang S (2021) Bearing capacity of strip footing on Hoek-Brown rock mass subjected to eccentric and inclined loading. Transp Infrastruct Geotechnol 8:189-200

Keawsawasvong S, Ukritchon B (2017) Undrained lateral capacity of I-shaped concrete piles. Songklanakarin J Sci Technol 39(6):751-758

Keawsawasvong S, Ukritchon B (2020) Design equation for stability of shallow unlined circular tunnels in HoekBrown rock masses. Bull Eng Geol Env 79:4167-4190

Kumar J, Ghosh P (2007a) Ultimate bearing capacity of two interfering rough strip footings. Int $\mathrm{J}$ Geomech ASCE 7(1):53-62

Kumar J, Ghosh P (2007b) Upper bound limit analysis for finding interference effect of two nearby strip footings on sand. Geotech Geol Eng 25(5):499-507

Kumar J, Kouzer KM (2008) Bearing capacity of two interfering footings. Int $\mathbf{J}$ Numer Anal Meth Geomech 32(3):251-264

Kumar J, Mohapatra D (2017) Lower-bound finite elements limit analysis for Hoek-Brown materials using semidefinite programming. J Eng Mech 143(9):04017077

Kumar J, Bhattacharya P (2010) Bearing capacity of interfering multiple strip footings by using lower bound finite elements limit analysis. Comput Geotech 37(5):731-736

Lavasan AA, Ghazavi M, Blumenthal A, Schanz T (2018) Bearing capacity of interfering strip footings. J Geotech Geoenviron Eng 144(3):04018003

Mabrouki A, Benmeddour D, Frank R, Mellas M (2010) Numerical study of the bearing capacity for two interfering strip footings on sands. Comput Geotech 37:431-439

Mansouri M, Imani M, Fahimifar A (2019) Ultimate bearing capacity of rock masses under square and rectangular footings. Comput Geotech 111:1-9

Mao N, Al-Bittar T, Soubra A-H (2012) Probabilistic analysis and design of strip foundations resting on rocks obeying Hoek-Brown failure criterion. Int J Rock Mech Min Sci 49:45-58

Merifield RS, Lyamin AV, Sloan SW (2006) Limit analysis solutions for the bearing capacity of rock masses using the generalized Hoek-Brown criterion. Int J Rock Mech Min Sci 43(6):920-937

OptumCE 2019, OptumG2. Copenhagen, Denmark: Optum Computational Engineering. See https://optumce.com/ (accessed on 10 August 2019).

Pal A, Ghosh P, Majumder M (2016) Interaction effect of two closely spaced skirted strip foundations in cohesionless 
soil using upper-bound limit analysis. Int $\mathrm{J}$ Geomech 17(2):06016022

Saada Z, Maghous S, Garnier D (2008) Bearing capacity of shallow foundations on rocks obeying a modified HoekBrown failure criterion. Comput Geotech 35:144-154

Serrano A, Olalla C (1994) Ultimate bearing capacity of rock masses. Int J Rock Mech Mining Sci Geomech Abstracts 31(2):93-106

Serrano A, Olalla C (1998a) Ultimate bearing capacity of an anisotropic discontinuous rock mass, part I: basic modes of failure. Int J Rock Mech Min Sci 35(3):301-324

Serrano A, Olalla C (1998b) Ultimate bearing capacity of an anisotropic discontinuous rock mass, part II: determination procedure. Int J Rock Mech Min Sci 35(3):325-348

Serrano A, Olalla C, Gonzalez J (2000) Ultimate bearing capacity of rock masses based on the modified HoekBrown criterion. Int J Rock Mech Min Sci 38(8):1217. https://doi.org/10.1016/S1365-1609(00)00028-9

Shamloo S, Imani N (2021) Upper bound solution for the bearing capacity of two adjacent footings on rock masses. Comput Geotech 129:103855

Shiau JS, Lyamin AV, Sloan SW (2003) Rigorous solutions of classical lateral earth pressures. In: Proceedings of the $6^{\text {th }}$ Australia-New Zealand young geotechnical professionals conference, Gold Coast, Australia., pp 162-167

Shiau JS, Lyamin AV, Sloan SW (2006) Application of pseudostatic limit analysis in geotechnical earthquake design. In: Schweiger H (ed) Numerical methods in geotechnical engineering. Taylor \& Francis Group, London, pp 249-255

Shiau J, Al-Asadi F (2020a) Three-dimensional heading stability of twin circular tunnels. Geotech Geol Eng 38(3):2973-2988. https://doi.org/10.1007/ s10706-020-01201-z

Shiau J, Al-Asadi F (2020b) Two-dimensional tunnel heading stability factors Fc, Fs and Fr. Tunn Undergr Space Technol. https://doi.org/10.1016/j.tust.2020.103293

Shiau J, Al-Asadi F (2020c) Stability analysis of twin circular tunnels using shear strength reduction method, Géotechnique Letters, 10(2), 311-319. Institution of Civil Engineers. https://doi.org/10.1680/jgele.19.00003

Shiau J, Al-Asadi F (2021a) Twin tunnels stability factors Fc, Fs and F $\gamma$. Geotech Geol Eng 39:335-345. https://doi.org/ 10.1007/s10706-020-01495-z

Shiau J, Al-Asadi F (2021) Revisiting circular tunnel stability using Broms and Bennermarks' original stability number.
Int J Geomech 21(5):06021009. https://doi.org/10.1061/ (ASCE)GM.1943-5622.0001996

Shiau J, Chudal B, Mahalingasivam K, Keawsawasvong S (2021a) Pipeline burst-related ground stability in blowout condition. Transportation Geotechnics 29:100587. https:// doi.org/10.1016/j.trgeo.2021.100587

Shiau J, Keawsawasvong S, Chudal B, Mahalingasivam K, Seehavong S (2021b) Sinkhole stability in elliptical cavity under collapse and blowout conditions. Geosciences 11(10):42. https://doi.org/10.3390/geosciences 11100421

Shiau J, Lee J-S, Al-Asadi F (2021c) Three-dimensional stability analysis of active and passive trapdoors. Tunn Undergr Space Technol 107:103635. https://doi.org/10.1016/j.tust. 2020.103635

Sloan SW (2013) Geotechnical stability analysis. Géotechnique 63(7):531-572

Stuart JG (1962) Interference between foundations, with special reference to surface footings in sand. Geotechnique 12(1):15-22

Ukritchon B, Keawsawasvong S (2017) Error in Ito and Matsui's limit equilibrium solution of lateral force on a row of stabilizing piles. J Geotech Geoenviron Eng ASCE 143(9):02817004

Ukritchon B, Keawsawasvong S (2018) Three-dimensional lower bound finite element limit analysis of Hoek-Brown material using semidefinite programming. Comput Geotech 104:248-270

Yang XL, Yin JH (2005) Upper bound solution for ultimate bearing capacity with modified Hoek-Brown failure criterion. Int J Rock Mech Min Sci 42:550-560

Yang F, Zheng XC, Sun XL, Zhao LH (2017) Upper-bound analysis of $\mathrm{N} \gamma$ and failure mechanisms of multiple equally spaced strip footings. Int J Geomech 17(9):06017016

Yodsomjai W, Keawsawasvong S, Lai VQ (2021) Limit analysis solutions for bearing capacity of ring foundations on rocks using Hoek-Brown failure criterion. Int J Geosynth Ground Eng 7:29

Yodsomjai W, Keawsawasvong S, Likitlersuang S (2021b) Stability of unsupported conical slopes in Hoek-Brown rock masses. Transp Infrastruct Geotechnol 8:278-295

Publisher's Note Springer Nature remains neutral with regard to jurisdictional claims in published maps and institutional affiliations. 